\title{
Therapeutics Development for Spinal Muscular Atrophy
}

\author{
Charlotte J. Sumner \\ Neurogenetics Branch, National Institute of Neurological Disorders and Stroke, National Institutes of Health, \\ Bethesda, Maryland 20892
}

\begin{abstract}
Summary: Spinal muscular atrophy is an autosomal recessive motor neuron disease that is the leading inherited cause of infant and early childhood mortality. Spinal muscular atrophy is caused by mutation of the telomeric copy of the survival motor neuron gene $(S M N 1)$, but all patients retain a centromeric copy of the gene, SMN2. SMN2 produces reduced amounts of full-length SMN mRNA, and spinal muscular atrophy likely results from insufficient levels of SMN protein in motor neurons. The SMN protein plays a well-established role in assembly of the spliceosome and may also mediate mRNA trafficking in the axon and nerve terminus of neurons. In patients, spinal muscular atrophy disease severity correlates inversely with increased SMN2 gene copy number and, in transgenic mice lack-
\end{abstract}

ing endogenous SMN, increasing SMN2 gene copy number from two to eight prevents the SMA disease phenotype. These observations suggest that increasing SMN expression levels may be beneficial to SMA patients. Currently pursued therapeutic strategies for SMA include induction of SMN2 gene expression, modulation of splicing of SMN2-derived transcripts, stabilization of SMN protein, neuroprotection of SMN deficit neurons, and SMN1 gene replacement. Early clinical trials of candidate therapeutics are now ongoing in SMA patients. Clinical trials in this disease present a unique set of challenges, including the development of meaningful outcome measures and disease biomarkers. Key Words: Spinal muscular atrophy, motor neuron, survival motor neuron.

\section{INTRODUCTION}

When used broadly, the term spinal muscular atrophy describes a collection of inherited and acquired diseases characterized by $\alpha$-motor neuron loss in the spinal cord causing muscle weakness and atrophy. These disorders, which include spinal and bulbar muscular atrophy (Kennedy's disease) and the distal spinal muscular atrophies (hereditary motor neuropathies), are distinguished by their differing clinical presentations, inheritance patterns, and causative gene abnormalities. Spinal muscular atrophy (SMA) is also the name given to the most common form of these disorders caused by mutation of the survival motor neuron $(S M N)$ gene. With an incidence of approximately 1 in 10,000 live births and a carrier frequency of 1 in $50,,^{1,2}$ this autosomal recessive disease is the leading inherited cause of infant mortality. Over the last 10 years, research efforts have led to the discovery of the genetic basis of SMA, an understanding of some of the functions of the survival motor neuron $(\mathrm{SMN})$ protein, and the development of SMA animal models that

Address correspondence and reprint requests to Charlotte J. Sumner, M.D., Neurogenetics Branch, National Institute of Neurological Disorders and Stroke, National Institutes of Health, 35 Convent Drive, Building 35, Room 2A1010, Bethesda, MD 20892. closely mimic the human disease. This work has provided the groundwork for the identification of promising targets for SMA therapeutics.

\section{CLINICAL AND PATHOLOGICAL FEATURES OF SPINAL MUSCULAR ATROPHY}

Spinal muscular atrophy was first described in the 1890s by Guido Werdnig of the University of Vienna and Johann Hoffman of Heidelberg University. The cardinal signs of SMA in all patients are muscle weakness and atrophy due to motor neuron loss. The pattern of weakness is symmetrical and proximal, with the legs more affected than the arms and the arms more affected than the facial muscles and diaphragm. SMA disease severity is heterogeneous and is classified into three types: types I, II, and III, based on international consensus. ${ }^{3}$ This classification based primarily on achievement of early motor milestones provides clinical and research utility (Table 1), although it is recognized that the boundaries between types are arbitrary and the disease actually has a continuous range of severity. Approximately 50\% of SMA patients have type I disease (Werdnig-Hoffman disease). This form of the disease is characterized by severe, generalized muscle weakness and hypotonia at 
TABLE 1. Clinical Classification of SMA

\begin{tabular}{clll}
\hline SMA Type & Age of Onset & \multicolumn{1}{c}{ Motor Milestones } & Average Age of Death \\
\hline I & $<6$ months & Unable to sit without support & $<2$ years \\
II & $<18$ months & Sit independently, unable to stand or walk unaided & $>3^{\text {rd }}$ decade \\
III & $>18$ months & Stand and walk independently & Normal life expectancy \\
\hline
\end{tabular}

birth or within the first 6 months of life. There is often severe involvement of the intercostal muscles with relative sparing of the diaphragm causing a bell-shaped chest. Patients never achieve the ability to sit, and death usually occurs from respiratory insufficiency within the first 2 years without ventilatory support. Patients with type II SMA have onset after 6 months of age and before 18 months of age. They achieve the ability to sit unsupported but never stand or walk unaided. Prognosis in this group is largely dependent of the degree on respiratory involvement. Survival for decades can be expected with aggressive respiratory management. Patients with type III SMA (Kugelberg-Welander disease) usually have their first symptoms between 18 months of age and early childhood. They are able to stand and walk independently at some point during their disease course but often become wheelchair bound during youth or adulthood. Life expectancy is not usually reduced in this group. There are also some patients who have onset in late childhood or adulthood (as late as the fifth or sixth decade). Some investigators have classified these cases as SMA type IV. Natural history studies indicate that, regardless of SMA type, disease progression and life expectancy strongly correlate with age of onset. ${ }^{4}$

The disease course in SMA is distinct from other degenerative motor neuron diseases such as amyotrophic lateral sclerosis (ALS). Rather than an inexorably progressive disease course after onset, patients with SMA tend to have the greatest rate of loss of muscle power at disease onset. ${ }^{5}$ This may manifest as a period during which there is clear loss of strength or there may be only the absence of normal motor milestone gains with early growth and development. After this early phase, the rate of loss of muscle strength may slow or stabilize for many years in surviving patients. A recent study indicated that the rate of motor neuron loss may mirror this clinical disease course. In a small number of patients followed longitudinally, the rate of denervation as assessed by motor unit number estimation (MUNE) and maximum compound motor action potential amplitude studies was greatest at onset of disease. ${ }^{6}$ In some patients late deterioration in functional abilities may result from the secondary effects of scoliosis and contractures rather than further motor neuron loss causing changes in muscle strength.

The predominant pathological feature of autopsy studies of patients with SMA is loss of motor neurons in the ventral horn of the spinal cord and in brain stem motor nuclei. ${ }^{7}$ Upper motor neurons and the corticospinal tracts are preserved, however ballooned neurons have been described within Clarke's nucleus of the spinal cord, in the ventrolateral region of the thalamus, and within the dorsal root ganglia in type I SMA autopsies, indicating that other neuronal types can be involved. Muscle biopsies in patients with type III SMA show changes typical of chronic neurogenic atrophy, with small angular fibers, grouped atrophy, and fiber type grouping. In contrast, SMA type I and type II muscle biopsies often show large groups of small, rounded atrophic fibers that can involve the whole fascicle. Rather than grouped atrophic fibers of the same type, fibers are often in a normal checkerboard pattern of interspersed type I and II fibers. Only scattered hypertrophic type I fibers are present. In SMA type I muscle, in particular, many of the small muscle fibers have an immature appearance, with central nuclei. In the past the diagnosis of SMA largely relied on demonstrating these muscle biopsy findings, but the availability of genetic testing has obviated the need for this invasive test.

\section{GENETIC BASIS OF SMA}

The SMA disease gene was mapped by linkage analysis to a complex region of chromosome $5 \mathrm{q}$ in $1990 .{ }^{8,9} \mathrm{In}$ humans this region contains a large inverted duplication and consequently at least four genes that are present in telomeric and centromeric copies: survival motor neuron gene $(S M N)$, neuronal apoptosis inhibitor protein gene $(N A I P)$, basal transcription factor subunit $\mathrm{p} 44$ gene, and the gene encoding a protein of unknown function, H4F5t. In 1995, Lefebvre et al. ${ }^{10}$ reported that homozygous mutations in the telomeric copy of the SMN gene (SMNI) cause SMA. The mutations are most often deletions involving at least exons 6 through 8 , but there can also be nonsense, frameshift, or missense mutations. ${ }^{11}$ Although $5-10 \%$ of the normal population lacks the centromeric copy of $S M N$ (SMN2), all patients with SMA retain the $S M N 2$ gene. SMN1 and SMN2 differ by five nucleotides; however, only one difference appears to be functionally important: a translationally silent $\mathrm{C} \rightarrow \mathrm{T}$ transition located within an exonic splicing region of SMN2 that leads to frequent exon 7 skipping during transcription of SMN2. ${ }^{12,13}$ Consequently, while SMN1 produces fulllength transcripts, the majority of transcripts that arise 


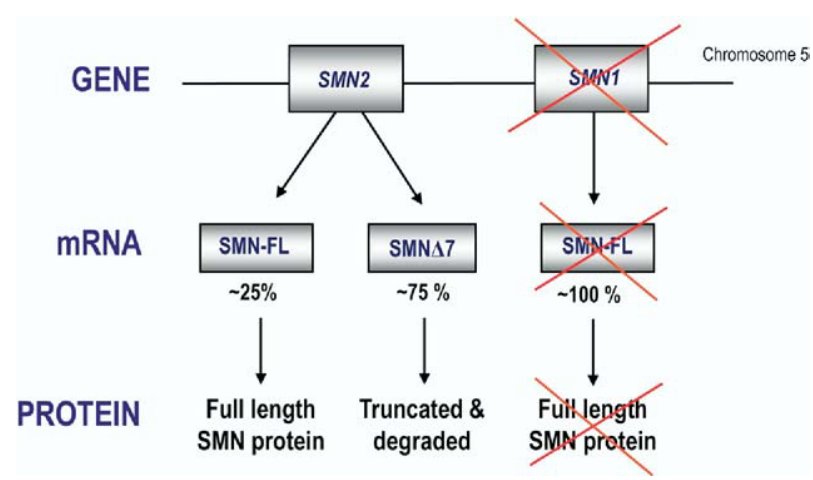

FIG. 1. In normal individuals, most full-length $S M N$ transcript and protein arises from the SMN1 gene. Patients with SMA have homozygous mutations in the SMN1 gene but retain at least one copy of the SMN2 gene. During transcription of SMN2, exon 7 is frequently skipped. Consequently, a majority of transcripts that arise from SMN2 lack exon 7 and codes for truncated protein that is rapidly degraded; a minority includes exon 7 and codes for full-length protein. SMA likely results from a deficiency of full-length SMN protein. Reproduced from Sumner CJ, Fischbeck, KH. Spinal muscular atrophy. In: Neurobiology of Disease (Gilman S, ed). San Diego: Elsevier (in press). ${ }^{14}$

from SMN2 lack exon 7 (FIG. 1). The transcripts lacking exon 7 encode a truncated protein that has impaired ability to oligomerize and associate with its binding partners and may be rapidly degraded. ${ }^{15,16} S M N 2$ is therefore unable to compensate completely for the loss of SMN1, and SMA likely results from a deficiency of full-length SMN protein. Several studies have shown that full-length SMN mRNA and protein are reduced in cell lines and tissues derived from type I SMA patients compared with controls. ${ }^{17-20}$

The SMA chromosomal region is unstable, and gene conversion events of SMN1 to SMN2 mean that the $S M N 2$ gene copy number varies in the population. The SMN2 copy number in SMA patients has a very important modifying effect on disease severity. ${ }^{21}$ Most patients with SMA type I have one or two SMN2 copies, most patients with type II have three SMN2 copies, and most patients with SMA type III have three or four SMN2 copies. ${ }^{22}$ Three unaffected family members of SMA patients with confirmed SMN1 deletion were shown to have five copies of $S M N 2 .{ }^{23}$ It has also been demonstrated in cell lines isolated from patients that increased levels of full-length SMN2 transcript and SMN protein correlate with increased copy number of the SMN2 genes and decreased disease severity. ${ }^{17-19}$ Thus, SMN2 copy number may explain much of the phenotypic variation in SMA; however, there have been rare families reported in whom markedly different degrees of disease severity were present in siblings with the same SMN2 copy number. ${ }^{24}$ There are ongoing efforts to identify other diseasemodifying factors in such kindreds.

\section{SMN PROTEIN}

SMN is a ubiquitously expressed protein with a molecular weight of $38 \mathrm{kDa}$. It has been highly conserved through evolution. SMN is present in both the cytoplasm and the nucleus. In the nucleus, it is concentrated in punctate structures called "gems" that overlap with or are closely apposed to Cajal bodies (FIG. 2). ${ }^{26}$ Cajal bodies contain high levels of factors involved in transcription and processing of many types of nuclear RNAs. Gem number in cell lines or tissues from SMA patients correlates inversely with disease severity, with type I patients showing few or no gems. ${ }^{27}$

The SMN protein has several identified motifs, including a lysine-rich basic region encoded by exon 2 , a Tudor motif (which may be important in RNA processing) encoded by exon 3, a polyproline region encoded by exons 4 and 5, and a region with several tyrosine-glycine (Y-G) pairs encoded by exon 6. Missense mutations have been identified in several of these regions, suggesting that each of these domains may be functionally important. SMN has been shown to oligomerize and form a stable multiprotein complex with at least six other proteins: Gemins 2 through 7. ${ }^{28}$ This SMN complex interacts with several other proteins, including the Sm and Sm-like proteins, RNA helicase A, fibrillarin, GAR1, and the ribonuclear proteins (RNP) hnRNP U, hnRNP Q, and hnRNP R. The common feature of these proteins is a domain rich in arginine $(\mathrm{R})$ and glycine $(\mathrm{G})$ residues that is essential for the SMN interaction. Modification of specific arginine residues within these RG-rich domains by symmetrical dimethylation enhances the affinity of several of these proteins for SMN. ${ }^{29,30}$

Many of the SMN interacting proteins are components

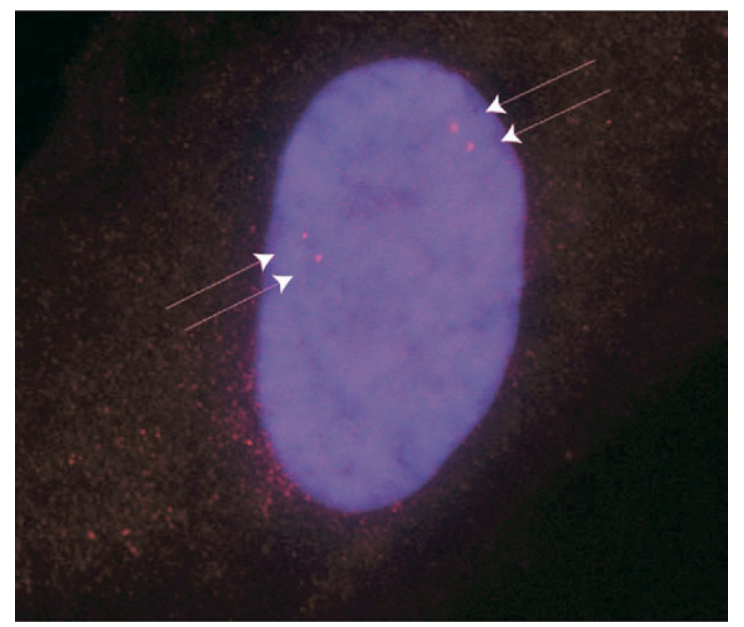

FIG. 2. The SMN protein forms punctuate structures in the nucleus called gems. Pictured is the nucleus (blue) of a fibroblast cell isolated from a SMA patient with four gems (red, arrows). Adapted from Sumner CJ, Huynh TN, Markowitz JA et al. Valproic acid increases SMN levels in spinal muscular atrophy patient cells. Ann Neurol 54:647-654, 2003. ${ }^{25}$ 
of various RNP complexes that are involved in distinct aspects of RNA processing. The SMN complex may therefore play a role in diverse aspects of RNA metabolism, including pre-RNA splicing, transcription, and metabolism of ribosomal RNAs. Presently, the best-characterized function of the SMN complex is regulating the assembly of a specific class of RNA-protein complexes, the uridine-rich small nuclear ribonuclear proteins (snRNPs) (reviewed in Yong et al. ${ }^{31}$ ). The snRNPs are a critical component of the spliceosome ${ }^{32}$; a large RNAprotein complex that catalyzes pre-mRNA splicing. The biogenesis of snRNPs involves a complex series of steps. First, a small nuclear RNA (snRNA) is transcribed by RNA polymerase II and rapidly exported to the cytoplasm. In the cell cytoplasm, the SMN complex mediates the ATP-dependent assembly of a ring of Sm proteins (B or $\mathrm{B}^{\prime}, \mathrm{D} 1, \mathrm{D} 2, \mathrm{D} 3, \mathrm{E}, \mathrm{F}$, and G) around a Sm site on the correct snRNA molecule. To mediate this assembly, SMN interacts directly with Sm proteins and the snRNA and provides specificity to the assembly process. After proper Sm core assembly, there is $5^{\prime}$-cap hypermethylation and $3^{\prime}$-end processing of the snRNA. The complex is then imported to the nucleus to process newly transcribed pre-mRNA into mature RNA. Recent work shows that SMN-mediated snRNP assembly may decrease with development and neuronal differentiation ${ }^{33}$ and reduced levels of SMN protein present in patientderived cells correlates with defects in snRNP assembly. ${ }^{34}$ It remains unknown, however, how this deficit in snRNP assembly might cause selective degeneration of motor neurons.

In addition to its activity in snRNP assembly, SMN may have other functions in motor neurons. The SMN protein can form granules that are actively transported and associated with $\beta$-actin mRNA in neuronal processes and growth cones. ${ }^{35}$ This localization may be facilitated by a 5 -aa motif present in exon 7 (QNQKE) of SMN. It has also been shown that, in neuronal processes, SMN binds the protein hnRNP that in turn binds to the $3^{\prime}$ untranslated region of $\beta$-actin mRNA. ${ }^{36}$ This interaction is required for the efficient transport of $\beta$-actin mRNA to growth cones of motor neurons. Motor neurons isolated from mice deficient in SMN show shortened axons and small growth cones, which are deficient in $\beta$-actin mRNA and protein. $\beta$-Actin mRNA and protein localization in the growth cone are known to be necessary for axonal outgrowth, as the actin cytoskeleton is the driving force for growth cone mobility. Actin dynamics are regulated by a series of actin-binding proteins. One of these proteins, profilin, has been shown to bind the proline-rich region of SMN and to colocalize with SMN in neuronal processes. ${ }^{37}$ These studies raise the possibility that SMN is important in the transport of mRNPs and mRNAs in the motor neuron axon and growth cone and that this function is critical for normal motor neuron outgrowth and maintenance.

\section{ANIMAL MODELS OF SMA}

The development of animal models of SMA not only yields important insights into disease pathogenesis but also provides essential in vivo systems for identifying and validating the efficacy of potential therapeutics. The SMN2 gene is unique to humans; most other organisms possess a single copy of the $S M N$ gene. Nematode, fly, and mouse models with no functional SMN protein have a uniformly early embryonic lethal phenotype.

A SMA Drosophila model was established when several missense mutations in the Drosophila smn gene were identified that resulted in elimination of the ability of the resulting protein to self-associate. ${ }^{38}$ The resulting mutant embryos survived to the late larval stage, but only because of maternal contribution of wild-type SMN in these early life stages. Before death, these larvae develop severe motor abnormalities associated with disorganization of the neuromuscular junction and impaired clustering of postsynaptic neurotransmitter receptors. This phenotype could be rescued by expression of wild-type SMN protein in both motor neuron and muscle but not in either tissue alone, suggesting that SMN deficiency causes defects of both the presynaptic and postsynaptic sides of the neuromuscular junction.

A zebrafish model of SMA was created by using morpholino antisense oligonucleotide "knockdown" technology to decrease the level of endogenous SMN protein to approximately $60 \% .{ }^{39}$ These fish showed defects in motor neuron axonal outgrowth and pathfinding during development, without abnormalities of other neuronal types or in muscle, suggesting that Smn protein has an essential role in motor neuron development (FIG. 3). Single neuron knockdowns showed that these effects were cell autonomous. A recent study demonstrated that knockdown of the SMN-interacting protein Gemin2 also resulted in this phenotype and that coinjection of purified U snRNPs into SMN-deficient or Gemin2-deficient zebrafish embryos could rescue this phenotype. This study suggests that this motor neuron deficit is directly caused by insufficient levels of snRNPs. ${ }^{40}$

To overcome the embryonic lethality of Smn (-I-) mice and to create mouse models of SMA with a clear behavioral phenotype, two different strategies were pursued. Frugier et al. ${ }^{41}$ made a conditional knockout of exon 7 of the murine Smn gene in specific tissues using the Cre-LoxP system. When exon 7 was deleted from neuronal cells, mice displayed a SMA phenotype with rapid motor deterioration and death at 4 weeks of age. Pathologically there was aberrant cytoskeletal organization at the neuromuscular junction, impaired axonal sprouting, and loss of motor axons, but only a mild 

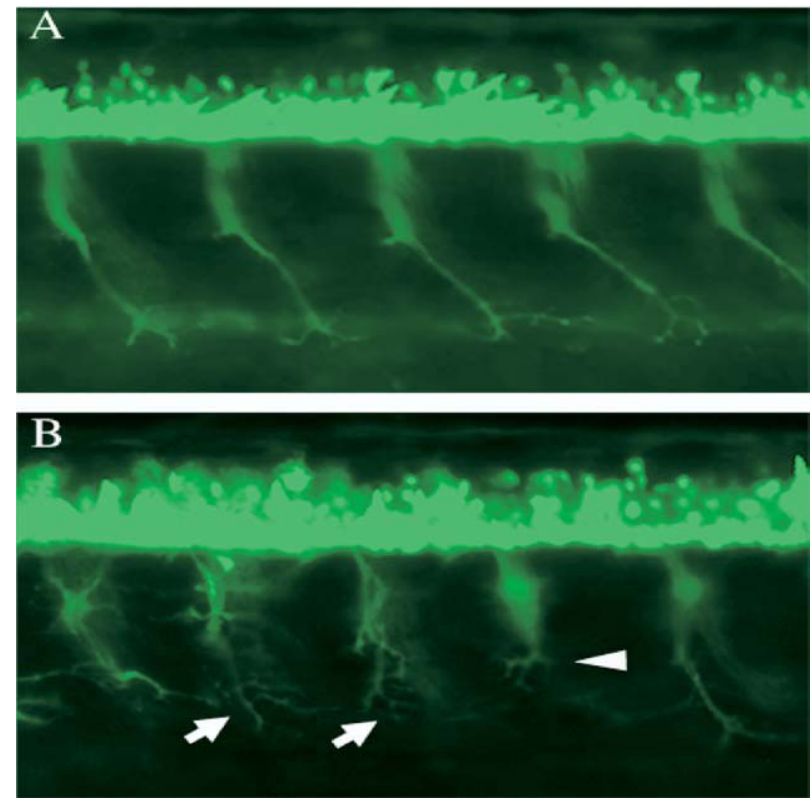

FIG. 3. Motor neurons of zebrafish without (A) and with (B) smn knockdown. Pictured are lateral views of GFP-labeled motoneurons in wild-type (A) and smn morphilino-injected (B) embryos at $50 \mathrm{~h}$ postfertilization. Examples of a severely truncated motor nerve (B; arrowhead) and severely branched motor nerves ( $\mathrm{B}$; arrows) are shown. Reproduced with permission from Christine Beattie and Michelle McWhorter.

reduction in motor neuron cell body number. These data suggested that loss of motor neuron cell bodies in SMA results from a dying back axonopathy. When SMN exon 7 was deleted specifically in skeletal muscle, mutant mice showed dystrophic changes in muscle, leading to muscle paralysis and death. ${ }^{16}$ These results, like those in Drosophila, may support the idea that there is primary involvement of muscle in addition to motor nerve in SMA. The second strategy that was used to generate SMA mice was to express the human SMN2 gene in the Smn knockout background. This was done by two different groups and each showed that this resulted in a SMA phenotype, the severity of which was dependent on SMN2 copy number. ${ }^{42,43}$ In this way, these mice closely model the human disease. Specifically, one group showed that mice expressing 1 copy of $S M N 2$ died within $12 \mathrm{~h}$ of birth and mice with 2 SMN2 copies survived to 6 days and showed reduced number of motor neurons by day $5 .{ }^{43}$ Mice expressing 8 to 16 copies of SMN2 were completely rescued from the SMA phenotype. These results dramatically confirm the modifying effect of the $S M N 2$ gene. This group has subsequently generated a line of mice that express high levels of a SMN transcript lacking exon 7 (SMN $\Delta 7$ ) in the $S M N 2+/$ + ;Smn-l- background. ${ }^{44}$ Lifespan in these mice is extended from approximately 5 to 14 days (FIG. 4), indicating that the SMN $\Delta 7$ transcript and protein may not be deleterious, as had been previously reported in an in vitro study, ${ }^{45}$ but rather may serve a protective role perhaps through complexing with the full-length protein.

The SMA mouse models that have been developed to date have confirmed the susceptibility of motor neurons to SMN deficiency and have verified that motor neuron degeneration can be prevented by increased dosage of $S M N 2$. The currently available lines of mice that carry the human SMN2 transgene are now being used to test potential therapeutics (see below), but these studies remain challenging, as mice with severe phenotypes die within 1 to 2 weeks of age, limiting the mode and duration of therapeutic delivery. Because of these difficulties, there are ongoing efforts to develop mice with intermediate disease severity phenotypes that can be more easily used for therapeutic trails. In addition, there is an effort to develop an inducible mouse model in which SMN can be activated during different stages of development. This may help to answer the question of when SMN replacement therapy must be delivered to patients to achieve a benefit.

\section{APPROACHES TO SMA THERAPEUTICS}

As a result of progress in understanding the genetic basis and pathophysiology of SMA, potential approaches to the treatment of SMA have emerged (FIG. 5). Based on the data from transgenic mouse models, one might predict that increased SMN protein levels would correct SMA before symptoms are seen. In symptomatic SMA patients, increased SMN levels might help to preserve remaining motor neuron function. Several strategies are being actively investigated to increase full-length SMN protein levels, including activating $S M N 2$ gene expression, preventing $S M N 2$ exon 7 skipping, and stabilizing SMN protein. Other strategies that are being pursued for SMA therapeutics involve identifying drugs that might provide neuroprotection to motor neurons with low SMN levels, replacing the $S M N 1$ gene using gene therapy, and

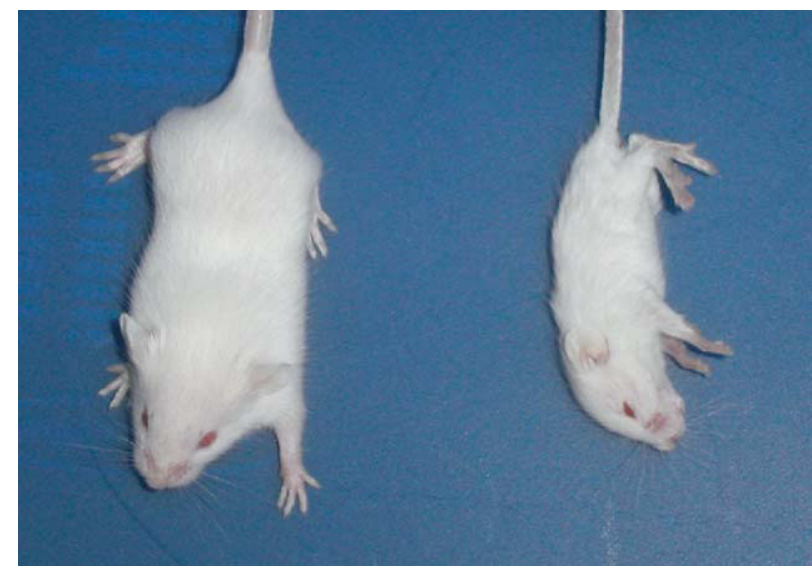

FIG. 4. SMA mice. At day 13 of life, a $S M N \Delta 7+/+/ S M N 2+/+$; Smn-/- SMA mouse (right) is small and profoundly weak compared with a normal littermate (left). ${ }^{44}$ 


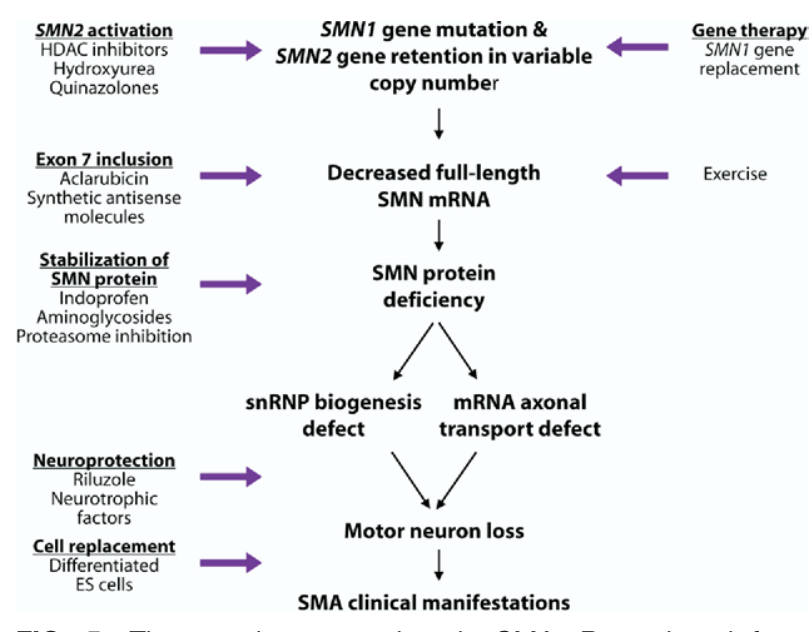

FIG. 5. Therapeutic approaches in SMA. Reproduced from Sumner CJ, Fischbeck, KH. Spinal muscular atrophy. In: Neurobiology of Disease (Gilman S, ed). San Diego: Elsevier (in press).

replacing motor neurons or muscle cells using embryonic stem cells.

\section{SMN2 gene activation: histone deacetylase} inhibitors and other drugs

The SMN2 gene is regulated by a promoter that is nearly identical in sequence and activity to the SMN1 promoter. ${ }^{46,47}$ An approximately 150 -bp region upstream of the translation initiation site contains the sequences necessary for minimal promoter activity, ${ }^{48}$ but regulatory sequences relevant to $S M N$ gene expression may be present as far as $4.6 \mathrm{~kb}$ upstream of the transcription initiation site. The $S M N$ promoter contains binding sites for and binds the cAMP-response element binding protein, the $\mathrm{Sp}$ family of proteins, and the interferon regulatory factor, all of which can modulate the promoter activity. ${ }^{48-50}$ In addition, it has been demonstrated that the $S M N$ promoter is associated with the histone deacetylase (HDAC) 1 and 2 proteins that may modulate the histone acetylation state at the $S M N$ promoter and play a role in determining $S M N 2$ gene expression. ${ }^{51}$

One class of drugs that has been investigated for the ability to activate the SMN2 gene is the HDAC inhibitors. Control of the acetylation state of histones is an important epigenetic mechanism regulating gene expression. When the $\mathrm{NH}_{2}$-terminus of core histones is acetylated in a region of chromatin, this region takes on a more relaxed chromatin structure that is more transcriptionally active due to increased accessibility of DNA to the transcriptional machinery. The level of histone acetylation is determined by the balance of activities of histone acetyltransferases, which acetylate histones, and HDACs, which deacetylate histones. During a smallmolecule screen of drugs that might increase SMN expression, Chang and colleagues ${ }^{52}$ demonstrated that sodium butyrate, one of the earliest discovered HDAC inhibitors, increased full-length SMN2 transcript levels and protein levels in lymphoblastoid cell lines derived from type I SMA patients. In addition, when sodium butyrate was administered to the pregnant mothers of SMA transgenic mice, it improved survival in their offspring. Subsequent studies have shown that the SMN2 promoter can be activated and full-length SMN mRNA and protein levels increased in SMA patient-derived cells by several other HDAC inhibitors, including phenylbutyrate, valproic acid, and suberoyl anilide hydroxamic acid. ${ }^{25,51,53,54}$ Two of these drugs (phenylbutyrate and valproic acid) have been in clinical use for many years for other indications and have well-established pharmacokinetic and safety profiles and good CNS penetration. Consequently, these drugs have been taken to early clinical trials in SMA patients, although efficacy in SMA animal models has not yet been proven. A pilot trial of phenylbutyrate in 10 patients with SMA in Italy showed that the drug was well tolerated. ${ }^{55}$ There are currently ongoing or planned clinical trials of phenylbutyrate and valproic acid in the United States, Italy, and Germany. (Table 2) There has also been interest in newer-generation HDAC inhibitors. In data presented in abstract form, sodium butyrate prodrugs have been shown to prolong survival in SMA mice. ${ }^{59}$ Interestingly, this survival benefit occurs without a demonstrable increase in SMN protein expression, indicating that this effect may be due to other neuroprotective effects, such as activation of antiapototic genes, as has been seen in a study of HDAC inhibitors in mice with ALS. ${ }^{60}$

Another drug that has been proposed to work by activating $S M N 2$ gene expression is hydroxyurea. In the past this compound has been shown activate the fetal globin gene and is used to treat patients with sickle cell disease and thalassemias. Hydroxyurea was shown to increase the amount of full-length SMN transcript and protein and gems in patient-derived lymphoblastoid cell lines ${ }^{61}$ and is currently being studied in clinical trials of SMA patients in Taiwan and in the United States. (Table 2)

Recently, a cell-based high-throughput screen of 550,000 compounds was performed to identify drugs that activate a 3.4-kb fragment of $S M N 2$ promoter present in a motor neuron-like cell line, NSC34 cells. ${ }^{62}$ Seventeen distinct compounds belonging to nine different scaffolds were identified. None appear to be acting as HDAC inhibitors. Two of these scaffolds, an indole compound and the quinazoline compounds, were confirmed to increase full-length SMN transcript and protein in patientderived fibroblast cells lines. The quinazoline scaffold is more attractive as it showed the highest potency, minimal cellular toxicity, and was amenable to chemical modification. This scaffold is currently ongoing a medicinal chemistry effort to improve its drug properties. 
TABLE 2. Completed, Ongoing, or Planned Clinical Trials in SMA

\begin{tabular}{|c|c|c|c|c|c|c|c|}
\hline Site & Drug & $\begin{array}{l}\text { Proposed } \\
\text { Mechanism of } \\
\text { Action }\end{array}$ & Type of Study & No. of Subjects & Primary Outcome & Duration & Result \\
\hline \multicolumn{8}{|l|}{ Completed } \\
\hline U.S. & Riluzole & Neuroprotection & $\begin{array}{l}\text { Placebo controlled } \\
\text { RCT }\end{array}$ & 10 Type I & Mortality & & $\begin{array}{l}\text { Safe, inconclusive } \\
\text { efficacy }\end{array}$ \\
\hline U.S. & Gabapentin & Neuroprotection & $\begin{array}{l}\text { Placebo-controlléd } \\
\text { RCT }\end{array}$ & $\begin{array}{l}65 \text { adults Types II } \\
\text { and III }\end{array}$ & QMT & 12 months & No effect ${ }^{57}$ \\
\hline Italy & Gabapentin & Neuroprotection & Open label RCT & $\begin{array}{l}120 \text { Types II and } \\
\text { III }\end{array}$ & QMT & 12 months & Minimal benefit ${ }^{58}$ \\
\hline Italy & Phenylbutyrate & $\begin{array}{l}\text { Activation } \\
\text { SMN2 }\end{array}$ & Open label pilot & $\begin{array}{l}10 \text { Types II and } \\
\text { III }\end{array}$ & $\begin{array}{c}\text { Blood SMN level, } \\
\text { Hammersmith }\end{array}$ & 7 days & Well tolerated ${ }^{55}$ \\
\hline Italy & Phenylbutyrate & $\begin{array}{l}\text { Activation } \\
\text { SMN2 }\end{array}$ & $\begin{array}{l}\text { Placebo-controlled } \\
\text { RCT }\end{array}$ & $\begin{array}{l}90 \text { Types II and } \\
\text { III }\end{array}$ & Hammersmith & 3 months & Analysis pending \\
\hline U.S. & Hydroxyurea & $\begin{array}{l}\text { Activation } \\
\text { SMN2 }\end{array}$ & Open label pilot & 33 Type II and III & $\begin{array}{l}\text { Muscle strength, } \\
\text { PFT and blood } \\
\text { SMN level }\end{array}$ & 8 weeks & Analysis pending \\
\hline Europe & $\begin{array}{l}\text { L-Acetyl- } \\
\text { carnitine }\end{array}$ & Neuroprotection & $\begin{array}{l}\text { Placebo-controlled } \\
\text { RCT }\end{array}$ & $\begin{array}{l}110 \text { patients age } \\
>5 \text { years }\end{array}$ & $\begin{array}{l}\text { Hand grip and } \\
\text { elbow flexion } \\
\text { strength }\end{array}$ & 9 months & Analysis pending \\
\hline \multicolumn{8}{|l|}{ Ongoing } \\
\hline U.S. & Phenylbutyrate & $\begin{array}{l}\text { Activation } \\
\text { SMN2 }\end{array}$ & Open label Phase I & Age $<2$ years & Safety & 12 months & \\
\hline U.S. & Valproic acid & $\begin{array}{l}\text { Activation } \\
\text { SMN2 }\end{array}$ & Open label Phase I & Age $>2$ years & Safety & 12 months & \\
\hline U.S. & $\begin{array}{l}\text { Valproic acid } \\
+ \text { carnitine }\end{array}$ & $\begin{array}{l}\text { Activation } \\
\text { SMN2 }\end{array}$ & $\begin{array}{l}\text { Placebo-controlled, } \\
\text { randomized, } \\
\text { intention to }\end{array}$ & $\begin{array}{l}90 \text { Type II \& III, } \\
\text { Ages 2-17 } \\
\text { years } \\
\text { treat }\end{array}$ & $\begin{array}{l}\text { M-HFMS and } \\
\text { PCFMS, } \\
\text { myometry, PFT }\end{array}$ & 13 months & \\
\hline France & Riluzole & Neuroprotection & $\begin{array}{l}\text { Placebo controlled } \\
\text { RCT }\end{array}$ & $\begin{array}{l}150 \text { Type II and } \\
\text { III }\end{array}$ & MFM & 2 years & \\
\hline U.S. & Riluzole & Neuroprotection & Open label & 44 Type I & Safety & 6 months & \\
\hline U.S. & Hydroxyurea & $\begin{array}{l}\text { Activation } \\
\text { SMN2 }\end{array}$ & $\begin{array}{l}\text { Placebo controlled } \\
\text { RCT }\end{array}$ & Type I & Survival & 6 months & \\
\hline U.S. & Hydroxyurea & $\begin{array}{l}\text { Activation } \\
\text { SMN2 }\end{array}$ & $\begin{array}{l}\text { Placebo controlled } \\
\text { RCT }\end{array}$ & Type II and III & $\begin{array}{l}\text { Muscle strength, } \\
\text { PFT and blood } \\
\text { SMN level }\end{array}$ & 6 months & \\
\hline \multicolumn{8}{|l|}{ Planned } \\
\hline Germany & Valproic acid & $\begin{array}{l}\text { Activation } \\
\text { SMN2 }\end{array}$ & $\begin{array}{l}\text { Placebo controlled } \\
\text { RCT }\end{array}$ & $\begin{array}{l}130 \text { Type I age }<6 \\
\text { months }\end{array}$ & Survival & 2 years & \\
\hline U.S. & Phenylbutyrate & $\begin{array}{l}\text { Activation } \\
\text { SMN2 }\end{array}$ & $\begin{array}{c}\text { Phase I dose } \\
\text { escalation }\end{array}$ & Type I, II, and III & Safety & & \\
\hline
\end{tabular}

$\mathrm{RCT}=$ randomized controlled trial; QMT=quantitative muscle testing; PFT = pulmonary function tests; M-HFMS= modified Hammersmith Functional Motor Scale for SMA (submitted for publication, Neuromusc Disord, Sept 2005); PCFMS = Project Cure Functional Motor Scale for SMA (undergoing validation); MFM=Mesure de Fonction Motrice pour les maladies neuromusculaires. 


\section{Exon 7 inclusion in SMN2 transcripts}

A strategy that could be successful in increasing SMN protein levels is to promote exon 7 inclusion in SMN2derived transcripts. The molecular mechanisms that direct splicing of the $S M N$ gene transcripts have been investigated in detail. Full-length SMN transcript is encoded by nine exons $(1,2 \mathrm{a}, 2 \mathrm{~b}, 3-8)$ and exons $1-7$ are translated into SMN protein. Two models have been proposed to explain the inhibitory effect of the $\mathrm{C}$ to $\mathrm{T}$ transition in SMN2 on exon 7 inclusion. ${ }^{63-65}$ According to the exonic splice enhancer model, SMN1 exon 7 contains a heptamer sequence motif that recruits the splicing factor SF2/ASF and promotes exon 7 inclusion. When this motif is interrupted by the $\mathrm{C} \rightarrow \mathrm{T}$ ( $\mathrm{U}$ in mRNA) transition that is present in SMN2 transcripts, the SF2/ ASF factor is not recruited, the $3^{\prime}$ splice site is not recognized, and exon 7 is excluded. ${ }^{64}$ The silencer model, in contrast, proposes that the $\mathrm{C}$ to $\mathrm{U}$ transition creates an exon silencer element that interacts with hnRNP A1 and represses exon 7 inclusion. ${ }^{65}$ It has been shown that exon 7 skipping can be partially overcome by a complex of splicing factors that binds an AG-rich exonic splicing enhancer region downstream of the heptamer motif. Htra2- $\beta 1$ binds directly and specifically to this DNA recognition sequence and facilitates exon 7 inclusion. ${ }^{66}$ The function of Htra2- $\beta 1$ is enhanced by interaction with hnRNP-G. ${ }^{67}$ Srp30c also binds Htra2- $\beta 1$ and may further stabilize the complex. ${ }^{68}$ There are likely to be many exonic and intronic splice enhancer and silencer motifs that play roles in SMN transcript splicing.

After a screen in patient fibroblasts, Andreassi et al. ${ }^{69}$ demonstrated that the chemotherapeutic drug aclarubicin stimulated exon 7 inclusion and consequently increased SMN protein levels. Unfortunately, the toxicity profile of this drug prohibits its long-term use in SMA patients. A nonpharmacological strategy to enhance exon 7 inclusion is the use of synthetic antisense oligonucleotides that bind to $S M N 2$-derived transcripts and promote exon 7 inclusion during splicing. Cartegni and $\mathrm{Krainer}^{70}$ have used small chimeric molecules consisting of an antisense moiety that recognizes and hybridizes to exon 7 sequence covalently linked to a peptide; these molecules mimic the function of SR proteins (a family of highly conserved splicing factors). Skordis et al. ${ }^{71}$ have used oligoribonucleotides that are complementary to exon 7 and contain exonic splicing enhancer motifs to provide trans-acting enhancers. Both groups have demonstrated that such strategies can work in vitro to increase exon 7 inclusion. One of the main challenges of this approach in SMA patients will be achieving efficient delivery of these constructs to motor neurons.

\section{Stabilizing SMN protein}

Related strategies for SMA treatment are to increase translation of SMN2-derived protein or to stabilize the protein that arises from the $S M N 2$ gene. In a cell-based high-throughput screen of approximately 47,000 compounds, indoprofen was shown to increase SMN2-derived protein, but not SMN1-derived protein. ${ }^{72}$ This drug does not act at the transcriptional level, but rather appears to act at the translational level, perhaps by increasing the efficiency of translation of SMN2-derived transcripts. In other work, Wolstencroft et al. recently showed that aminoglycosides increase SMN protein levels and gem counts in patient-derived fibroblasts. ${ }^{73}$ Aminoglycosides are known to alter translation by promoting read-through of stop codons. The authors speculate that these drugs enable read-through of the initial stop codon in exon 8 of SMN2 transcripts. This results in a SMN protein with a slightly elongated C-terminus, which promotes its stability. Unfortunately, both indoprofen and aminoglycosides have poor central nervous penetration. To apply these approaches to SMA patients, new compounds will need to be identified that retain this activity and penetrate the blood-brain barrier. It has also been demonstrated that the SMN protein is degraded by the ubiquitin-proteasome system and that drugs that inhibit this pathway increase SMN protein levels in patientderived fibroblasts. ${ }^{74}$ Further understanding of how the SMN protein is degraded may lead to other SMA therapeutic targets.

\section{Neuroprotection}

Another important goal in SMA therapeutics research is to identify ways to protect SMN-deficient motor neurons from degeneration. Unlike efforts to identify compounds that increase $S M N 2$ gene expression or exon 7 inclusion, there have not yet been cell-based highthroughput screens to identify compounds that might be neuroprotective, because an in vitro motor neuronal model of SMA has been lacking to date. Currently, there are efforts to develop such a model using embryonic stem cells differentiated into motor neurons.

Based on a candidate approach, several drugs have been chosen for investigation in SMA. Because of the modest efficacy in patients with ALS, riluzole has also been evaluated in SMA. Riluzole showed a modest benefit on survival of SMA mice with targeted deletion of exon 7 in neurons. ${ }^{75} \mathrm{~A}$ small clinical trial in type I SMA patients showed that the drug was well tolerated ${ }^{56}$ and two larger clinical trials are in progress in the United States and Europe (Table 2). Another preclinical study in SMA mice showed a beneficial response to the neurotrophic factor, cardiotrophin-1 (CT-1). ${ }^{76}$ Cardiotrophin-1 was delivered by intramuscular injection in an adenoviral vector and, even at low does, CT-1 was able to improve survival and delay the motor defect in SMA mice with targeted deletion of exon 7 in neurons. Neurotrophic factors deserve further study as potential neuroprotective drugs in SMA. Gabapentin was studied in two clinical 
trials in SMA patients, but unfortunately this drug showed no significant efficacy in these studies (Table 2)..$^{57,58}$

\section{Gene therapy and cell replacement}

A strategy that could theoretically lead to a cure for SMA is replacement of the SMN1 gene using a gene therapy approach. Unfortunately, development of gene therapy in general has been limited because of the technical difficulties of efficient gene delivery to target tissues as well as problems related to random insertion of the therapeutic gene into the host DNA. Nonetheless, a recent study in SMA mice showed promising early results. After injection of the SMN1 gene packaged in a lentivector gene transfer system into muscle, the SMNI gene was retrogradely transported to and expressed in spinal motor neurons and led to a modest increase in lifespan of SMA mice by approximately 3-5 days. ${ }^{77}$ Another strategy that might eventually play a role in SMA treatment is cell replacement. Embryonic stem (ES) cells are pluripotent cells that can be differentiated into motor neurons. In a recent study, differentiated ES cells were transplanted into the spinal cord of rats with Sindbus virus-induced motor neuron injury. ${ }^{78}$ The cells survived and produced axons that were able to grow into the ventral root.

\section{Other approaches}

Because forced exercise was found to be of benefit in ALS mouse models, ${ }^{79,80}$ it was recently studied in SMA mice. In this study, type 2 SMA mice developed by Hsieh-Li et al. ${ }^{42}$ were subjected to a training protocol of forced run on a wheel or no training. Trained mice showed improved survival of approximately $57 \%$ as well as reduced motor neuron loss. Interestingly, there was also evidence of increased full-length SMN transcript and protein in spinal cord tissues from trained animals. The authors speculate that exercise may activate genes that promote exon 7 inclusion in SMN2-derived transcripts. ${ }^{81}$

\section{CHALLENGES OF CLINICAL TRIALS IN SMA PATIENTS}

Because of the progress in the understanding of the genetics and disease pathogenesis of SMA, we are now beginning clinical trials of candidate therapeutics. Designing successful clinical trials in SMA patients presents a series of difficult challenges, however. ${ }^{5}$ The wide variability of severity of this relatively rare disease makes it difficult to collect a homogeneous study population or to use the same outcome measures for all patients. Recent international consensus has emphasized the importance of designing and performing separate trials of patients with type I SMA and those with type II and III and even to stratify within these groups to obtain as homogeneous a study population as possible. ${ }^{82}$ In type I SMA trials, survival is the most frequent outcome measure, however, studies are ongoing to validate other outcome measures, including MUNE, functional motor scales, and respiratory measures. ${ }^{6,82}$ For patients with type II and type III disease there has been an effort to develop validated functional motor scales such as the Hammersmith or French Mesure de Fonction Motrice pour les maladies neuromusculaires, as well as validated quantitative muscle testing, MUNE, respiratory measures, and quality of life measures. ${ }^{6,82-84}$ Because of the distinctive disease course in SMA with plateaus in the rate of decline, it may be very difficult to demonstrate effects on these outcome measures. It is therefore very important to develop other biomarkers for SMA clinical trials. One potential biomarker in trials of drugs expected to work by increasing SMN is SMN levels in an accessible tissue such as peripheral blood. A recent study demonstrated the feasibility and reliability of a measure of SMN mRNA using quantitative reverse transcription PCR and of SMN protein using a cell immunoassay in the blood of SMA patients. ${ }^{85}$

\section{REMAINING QUESTIONS}

Great progress has been made in the last 10 years in SMA research. Although this has pointed to targets for therapeutics in SMA, important questions remain. Will SMN replacement work in SMA patients? If so, in what cells and tissues will SMN replacement be required? Is delivery to motor neurons sufficient, or must SMN also be delivered to muscle? How late in the disease process can SMN replacement rescue the phenotype? Do data suggesting that SMN has a developmental role in proper motor neuron outgrowth indicate that SMN must be delivered very early? Can the cause of the specific susceptibility of motor neurons to SMN deficiency be identified? Does motor neuron degeneration result directly from snRNP assembly deficiency, or does SMN have a unique function in motor neurons? Answers to these questions will likely lead to the identification of new targets for SMA therapeutics and ultimately effective treatment for the disease.

\section{REFERENCES}

1. Pearn J. Incidence, prevalence, and gene frequency studies of chronic childhood spinal muscular atrophy. J Med Genet 15:409413, 1978.

2. McAndrew PE, Parsons DW, Simard LR et al. Identification of proximal spinal muscular atrophy carriers and patients by analysis of SMNT and SMNC gene copy number. Am J Hum Genet 60: 1411-1422, 1997.

3. Munsat TL, Davies KE. International SMA consortium meeting (26-28 June 1992, Bonn, Germany). Neuromuscul Disord 2:423428,1992

4. Zerres K, Rudnik-Schoneborn S. Natural history in proximal spinal muscular atrophy: clinical analysis of 445 patients and suggestions 
for a modification of existing classifications. Arch Neurol 52:518-523, 1995.

5. Crawford TO. Concerns about the design of clinical trials for spinal muscular atrophy. Neuromuscul Disord 14:456-460, 2004

6. Swoboda KJ, Prior TW, Scott CB et al. Natural history of denervation in SMA: relation to age, SMN2 copy number, and function. Ann Neurol 57:704-712, 2005.

7. Ince SWaPG. Pathology of motor neuron disorders. In: Motor Neuron Disorders (Strong PJSaMJ, ed), pp 17-49. Philadelphia: Butterworth Heinemann, 2003.

8. Brzustowicz LM, Lehner T, Castilla LH et al. Genetic mapping of chronic childhood-onset spinal muscular atrophy to chromosome 5q11.2-13.3. Nature 344:540-541, 1990.

9. Melki J, Sheth P, Abdelhak S et al. Mapping of acute (type I) spinal muscular atrophy to chromosome 5q12-q14: The French Spinal Muscular Atrophy Investigators. Lancet 336:271-273, 1990.

10. Lefebvre S, Burglen L, Reboullet $\mathrm{S}$ et al. Identification and characterization of a spinal muscular atrophy-determining gene. Cell 80:155-165, 1995.

11. Wirth B. An update of the mutation spectrum of the survival motor neuron gene (SMN1) in autosomal recessive spinal muscular atrophy (SMA). Hum Mutat 15:228-237, 2000.

12. Lorson CL, Hahnen E, Androphy EJ, Wirth B. A single nucleotide in the SMN gene regulates splicing and is responsible for spinal muscular atrophy. Proc Natl Acad Sci USA 96:6307-6311, 1999.

13. Monani UR, Lorson CL, Parsons DW et al. A single nucleotide difference that alters splicing patterns distinguishes the SMA gene SMN1 from the copy gene SMN2. Hum Mol Genet 8:1177-1183, 1999.

14. Sumner CJ, Fischbeck, KH. Spinal muscular atrophy. In: Neurobiology of Disease (Gilman S, ed), San Diego: Elsevier (in press).

15. Lorson CL, Strasswimmer J, Yao JM et al. SMN oligomerization defect correlates with spinal muscular atrophy severity. Nat Genet 19:63-66, 1998.

16. Cifuentes-Diaz C, Frugier T, Tiziano FD et al. Deletion of murine SMN exon 7 directed to skeletal muscle leads to severe muscular dystrophy. J Cell Biol 152:1107-1114, 2001.

17. Lefebvre S, Burlet P, Liu Q et al. Correlation between severity and SMN protein level in spinal muscular atrophy. Nat Genet 16:265$269,1997$.

18. Coovert DD, Le TT, McAndrew PE et al. The survival motor neuron protein in spinal muscular atrophy. Hum Mol Genet 6:1205-1214, 1997.

19. Gavrilov DK, Shi X, Das K, Gilliam TC, Wang CH. Differential SMN2 expression associated with SMA severity. Nat Genet 20: 230-231, 1998.

20. Soler-Botija C, Cusco I, Caselles L, Lopez E, Baiget M, Tizzano EF. Implication of fetal SMN2 expression in type I SMA pathogenesis: protection or pathological gain of function? J Neuropathol Exp Neurol 64:215-223, 2005.

21. Parsons DW, McAndrew PE, Iannaccone ST, Mendell JR, Burghes $\mathrm{AH}$, Prior TW. Intragenic telSMN mutations: frequency, distribution, evidence of a founder effect, and modification of the spinal muscular atrophy phenotype by cenSMN copy number. Am J Hum Genet 63:1712-1723, 1998.

22. Feldkotter M, Schwarzer V, Wirth R, Wienker TF, Wirth B. Quantitative analyses of SMN1 and SMN2 based on real-time lightCycler PCR: fast and highly reliable carrier testing and prediction of severity of spinal muscular atrophy. Am J Hum Genet 70:358 -368, 2002.

23. Prior TW, Swoboda KJ, Scott HD, Hejmanowski AQ. Homozygous SMN1 deletions in unaffected family members and modification of the phenotype by SMN2. Am J Med Genet A 130:307310, 2004.

24. Parano E, Pavone L, Falsaperla R, Trifiletti R, Wang C. Molecular basis of phenotypic heterogeneity in siblings with spinal muscular atrophy. Ann Neurol 40:247-251, 1996.

25. Sumner CJ, Huynh TN, Markowitz JA et al. Valproic acid increases SMN levels in spinal muscular atrophy patient cells. Ann Neurol 54:647-654, 2003.

26. Liu Q, Fischer U, Wang F, Dreyfuss G. The spinal muscular atrophy disease gene product, SMN, and its associated protein
SIP1 are in a complex with spliceosomal snRNP proteins. Cell 90:1013-1021, 1997.

27. Patrizi AL, Tiziano F, Zappata S, Donati MA, Neri G, Brahe C. SMN protein analysis in fibroblast, amniocyte and CVS cultures from spinal muscular atrophy patients and its relevance for diagnosis. Eur J Hum Genet 7:301-309, 1999.

28. Paushkin S, Gubitz AK, Massenet S, Dreyfuss G. The SMN complex, an assemblyosome of ribonucleoproteins. Curr Opin Cell Biol 14:305-312, 2002.

29. Friesen WJ, Massenet S, Paushkin S, Wyce A, Dreyfuss G. SMN, the product of the spinal muscular atrophy gene, binds preferentially to dimethylarginine-containing protein targets. Mol Cell 7:1111-1117, 2001.

30. Friesen WJ, Paushkin S, Wyce A et al. The methylosome, a $20 \mathrm{~S}$ complex containing JBP1 and pICln, produces dimethylargininemodified Sm proteins. Mol Cell Biol 21:8289-8300, 2001.

31. Yong J, Wan L, Dreyfuss G. Why do cells need an assembly machine for RNA-protein complexes? Trends Cell Biol 14:226232, 2004.

32. Will CL, Luhrmann R. Spliceosomal UsnRNP biogenesis, structure and function. Curr Opin Cell Biol 13:290-301, 2001.

33. Gabanella F, Carissimi C, Usiello A, Pellizzoni L. The activity of the spinal muscular atrophy protein is regulated during development and cellular differentiation. Hum Mol Genet 14:3629-3642, 2005

34. Wan L, Battle DJ, Yong J et al. The survival of motor neurons protein determines the capacity for snRNP assembly: biochemical deficiency in spinal muscular atrophy. Mol Cell Biol 25:5543$5551,2005$.

35. Zhang HL, Pan F, Hong D, Shenoy SM, Singer RH, Bassell GJ. Active transport of the survival motor neuron protein and the role of exon-7 in cytoplasmic localization. J Neurosci 23:6627-6637, 2003.

36. Rossoll W, Jablonka S, Andreassi C et al. Smn, the spinal muscular atrophy-determining gene product, modulates axon growth and localization of beta-actin mRNA in growth cones of motoneurons. J Cell Biol 163:801-812, 2003.

37. Sharma A, Lambrechts A, Hao LT et al. A role for complexes of survival of motor neurons (SMN) protein with gemins and profilin in neurite-like cytoplasmic extensions of cultured nerve cells. Exp Cell Res 309:185-197, 2005

38. Chan YB, Miguel-Aliaga I, Franks C et al. Neuromuscular defects in a Drosophila survival motor neuron gene mutant. Hum Mol Genet 12:1367-1376, 2003.

39. McWhorter ML, Monani UR, Burghes AH, Beattie CE. Knockdown of the survival motor neuron $(\mathrm{Smn})$ protein in zebrafish causes defects in motor axon outgrowth and pathfinding. J Cell Biol 162:919-931, 2003.

40. Winkler C, Eggert C, Gradl D et al. Reduced U snRNP assembly causes motor axon degeneration in an animal model for spinal muscular atrophy. Genes Dev 19:2320-2330, 2005.

41. Frugier T, Tiziano FD, Cifuentes-Diaz C et al. Nuclear targeting defect of SMN lacking the C-terminus in a mouse model of spinal muscular atrophy. Hum Mol Genet 9:849-858, 2000.

42. Hsieh-Li HM, Chang JG, Jong YJ et al. A mouse model for spinal muscular atrophy. Nat Genet 24:66-70, 2000.

43. Monani UR, Sendtner M, Coovert DD et al. The human centromeric survival motor neuron gene (SMN2) rescues embryonic lethality in $\operatorname{Smn}(-/-)$ mice and results in a mouse with spinal muscular atrophy. Hum Mol Genet 9:333-339, 2000.

44. Le TT, Pham LT, Butchbach ME et al. SMNDelta7, the major product of the centromeric survival motor neuron (SMN2) gene, extends survival in mice with spinal muscular atrophy and associates with full-length SMN. Hum Mol Genet 14:845-857, 2005.

45. Kerr DA, Nery JP, Traystman RJ, Chau BN, Hardwick JM. Survival motor neuron protein modulates neuron-specific apoptosis. Proc Natl Acad Sci USA 97:13312-13317, 2000.

46. Echaniz-Laguna A, Miniou P, Bartholdi D, Melki J. The promoters of the survival motor neuron gene (SMN) and its copy (SMNc) share common regulatory elements. Am J Hum Genet 64:13651370, 1999.

47. Monani UR, McPherson JD, Burghes AH. Promoter analysis of the 
human centromeric and telomeric survival motor neuron genes (SMNC and SMNT). Biochim Biophys Acta 1445:330-336, 1999.

48. Rouget R, Vigneault F, Codio $\mathrm{C}$ et al. Characterization of the survival motor neuron (SMN) promoter provides evidence for complex combinatorial regulation in undifferentiated and differentiated P19 cells. Biochem J 385:433-443, 2005.

49. Baron-Delage S, Abadie A, Echaniz-Laguna A, Melki J, Beretta L. Interferons and IRF-1 induce expression of the survival motor neuron (SMN) genes. Mol Med 6:957-968, 2000.

50. Majumder S, Varadharaj S, Ghoshal K, Monani U, Burghes AH, Jacob ST. Identification of a novel cyclic AMP-response element (CRE-II) and the role of CREB-1 in the cAMP-induced expression of the survival motor neuron (SMN) gene. J Biol Chem 279: 14803-14811, 2004.

51. Kernochan LE, Russo ML, Woodling NS et al. The role of histone acetylation in SMN gene expression. Hum Mol Genet 14:1171$1182,2005$.

52. Chang JG, Hsieh-Li HM, Jong YJ, Wang NM, Tsai CH, Li H. Treatment of spinal muscular atrophy by sodium butyrate. Proc Natl Acad Sci USA 98:9808-9813, 2001.

53. Brichta L, Hofmann Y, Hahnen E et al. Valproic acid increases the SMN2 protein level: a well-known drug as a potential therapy for spinal muscular atrophy. Hum Mol Genet 12:2481-2489, 2003.

54. Andreassi C, Angelozzi C, Tiziano FD et al. Phenylbutyrate increases SMN expression in vitro: relevance for treatment of spinal muscular atrophy. Eur J Hum Genet 12:59-65, 2004.

55. Brahe C, Vitali T, Tiziano FD et al. Phenylbutyrate increases SMN gene expression in spinal muscular atrophy patients. Eur J Hum Genet 13:256-259, 2005.

56. Russman BS, Iannaccone ST, Samaha FJ. A phase 1 trial of riluzole in spinal muscular atrophy. Arch Neurol 60:1601-1603, 2003.

57. Miller RG, Moore DH, Dronsky V et al. A placebo-controlled trial of gabapentin in spinal muscular atrophy. J Neurol Sci 191:127131, 2001.

58. Merlini L, Solari A, Vita G et al. Role of gabapentin in spinal muscular atrophy: results of a multicenter, randomized Italian study. J Child Neurol 18:537-541, 2003.

59. Butchbach M, Le TT, Burghes AHM. Protective effects of butyrate analogues and prodrugs on a mouse model for spinal muscular atrophy. Neurosci Meeting 23:27, 2004.

60. Ryu H, Smith K, Camelo SI et al. Sodium phenylbutyrate prolongs survival and regulates expression of anti-apoptotic genes in transgenic amyotrophic lateral sclerosis mice. J Neurochem 93:10871093, 2005.

61. Grzeschik SM, Ganta M, Prior TW, Heavlin WD, Wang CH. Hydroxyurea enhances SMN2 gene expression in spinal muscular atrophy cells. Ann Neurol 58:194-202, 2005.

62. Jarecki J, Chen X, Bernardino A et al. Diverse small-molecule modulators of SMN expression found by high-throughput compound screening: early leads towards a therapeutic for spinal muscular atrophy. Hum Mol Genet 14:2003-2018, 2005.

63. Lorson CL, Androphy EJ. An exonic enhancer is required for inclusion of an essential exon in the SMA-determining gene SMN. Hum Mol Genet 9:259-265, 2000.

64. Cartegni L, Krainer AR. Disruption of an SF2/ASF-dependent exonic splicing enhancer in SMN2 causes spinal muscular atrophy in the absence of SMN1. Nat Genet 30:377-384, 2002.

65. Kashima T, Manley JL. A negative element in SMN2 exon 7 inhibits splicing in spinal muscular atrophy. Nat Genet 34:460463, 2003.

66. Hofmann Y, Lorson CL, Stamm S, Androphy EJ, Wirth B. Htra2beta 1 stimulates an exonic splicing enhancer and can restore full-length SMN expression to survival motor neuron 2 (SMN2). Proc Natl Acad Sci USA 97:9618-9623, 2000.
67. Hofmann Y, Wirth B. hnRNP-G promotes exon 7 inclusion of survival motor neuron $(\mathrm{SMN})$ via direct interaction with Htra2beta1. Hum Mol Genet 11:2037-2049, 2002.

68. Young PJ, DiDonato CJ, Hu D, Kothary R, Androphy EJ, Lorson CL. SRp30c-dependent stimulation of survival motor neuron (SMN) exon 7 inclusion is facilitated by a direct interaction with hTra2 beta 1. Hum Mol Genet 11:577-587, 2002.

69. Andreassi C, Jarecki J, Zhou J et al. Aclarubicin treatment restores SMN levels to cells derived from type I spinal muscular atrophy patients. Hum Mol Genet 10:2841-2849, 2001.

70. Cartegni L, Krainer AR. Correction of disease-associated exon skipping by synthetic exon- specific activators. Nat Struct Biol 10:120-125, 2003

71. Skordis LA, Dunckley MG, Yue B, Eperon IC, Muntoni F. Bifunctional antisense oligonucleotides provide a trans-acting splicing enhancer that stimulates SMN2 gene expression in patient fibroblasts. Proc Natl Acad Sci USA 100:4114-4119, 2003.

72. Lunn MR, Root DE, Martino AM et al. Indoprofen upregulates the survival motor neuron protein through a cyclooxygenase-independent mechanism. Chem Biol11:1489-1493, 2004.

73. Wolstencroft EC, Mattis V, Bajer AA, Young PJ, Lorson CL. A non-sequence-specific requirement for SMN protein activity: the role of aminoglycosides in inducing elevated SMN protein levels. Hum Mol Genet 14:1199-1210, 2005.

74. Chang HC, Hung WC, Chuang YJ, Jong YJ. Degradation of survival motor neuron (SMN) protein is mediated via the ubiquitin/ proteasome pathway. Neurochem Int 45:1107-1112, 2004

75. Haddad H, Cifuentes-Diaz C, Miroglio A, Roblot N, Joshi V, Melki J Riluzole attenuates spinal muscular atrophy disease progression in a mouse model. Muscle Nerve 28:432-437, 2003.

76. Lesbordes JC, Cifuentes-Diaz C, Miroglio A et al. Therapeutic benefits of cardiotrophin-1 gene transfer in a mouse model of spinal muscular atrophy. Hum Mol Genet 12:1233-1239, 2003.

77. Azzouz M, Le T, Ralph GS et al. Lentivector-mediated SMN replacement in a mouse model of spinal muscular atrophy. J Clin Invest 114:1726-1731, 2004.

78. Harper JM, Krishnan C, Darman JS et al. Axonal growth of embryonic stem cell-derived motoneurons in vitro and in motoneuron-injured adult rats. Proc Natl Acad Sci USA 101:7123-7128, 2004.

79. Kirkinezos IG, Hernandez D, Bradley WG, Moraes CT. Regular exercise is beneficial to a mouse model of amyotrophic lateral sclerosis. Ann Neurol 53:804-807, 2003.

80. Mahoney DJ, Rodriguez C, Devries M, Yasuda N, Tarnopolsky MA. Effects of high-intensity endurance exercise training in the G93A mouse model of amyotrophic lateral sclerosis. Muscle Nerve 29:656-662, 2004

81. Grondard C, Biondi O, Armand AS et al. Regular exercise prolongs survival in a type 2 spinal muscular atrophy model mouse. J Neurosci 25:7615-7622, 2005.

82. Bertini E, Burghes A, Bushby K, et al. 134th ENMC International Workshop: Outcome Measures and Treatment of Spinal Muscular Atrophy11-13 February 2005, Naarden, The Netherlands. Neuromuscul Disord 15:802-816, 2005.

83. Iannaccone ST. Outcome measures for pediatric spinal muscular atrophy. Arch Neurol 59:1445-1450,2002.

84. Iannaccone ST, Hynan LS. Reliability of 4 outcome measures in pediatric spinal muscular atrophy. Arch Neurol 60:1130-1136, 2003.

85. Sumner C, Kolb, SJ, Harmison, GG, Jeffries, NO, Schadt, K, Finkel, RS, Dreyfuss, G, Fischbeck, KH. SMN mRNA and protein levels in peripheral blood: biomarkers for SMA clinical trials. Neurology, in press. 